\title{
Antiviral mechanisms related to lactic acid bacteria and fermented food products
}

\author{
Zümrüt Begüm ÖGEL ${ }^{1, *}$ (D), Hale İnci ÖZTÜRK ${ }^{1}$
}

${ }^{1}$ Department of Food Engineering, Konya Food and Agriculture University, 42080 Meram, Konya, Turkey.

\author{
Article History \\ Received 30 May 2020 \\ Accepted 03 June 2020 \\ First Online 11 June 2020
}

\author{
* Corresponding Author \\ Tel.: +90 5326279162 \\ E-mail: \\ zumrut.ogel@gidatarim.edu.tr
}

\section{Keywords}

Antiviral effect

Paraprobiotics

Probiotics

Fermented food

\begin{abstract}
The Covid-19 pandemics laid stress on the significance of having a strong immune system in coping with viral infections. Nutrition is important in the modulation of our immune systems. Recent studies have shown that probiotics, most of which are lactic acid bacteria (LAB) naturally present in fermented food products, can boost the immune system of their host. Although responses are generally strain and dose dependent, in one way or another, most $L A B$ are capable of enhancing both the innate and the adaptive immune responses in animal model systems. In addition to their ability of boosting the immune system, LAB directly or indirectly by means of the fermentation process, can generate bioactive metabolites having antiviral properties, such as peptides. LAB are shown to have antiviral mechanisms that affect both upper respiratory tract and gastrointestinal viral infections. Not only live cells but also heat-killed cells of probiotics (paraprobiotics) are shown to be effective. These wide range of antiviral mechanisms suggest that the diversity of LAB in the food product is likely to enhance the variety and strength of health benefits obtained from fermented foods. Traditional fermented foods have significantly higher microbiodiversity with respect to the LAB species, as compared to those produced by commercial cultures. This is particularly valid for the Lactobacilli, where several species and strains have proven to be antiviral probiotics and are natural inhabitants of fermented foods at the same time. While drawing attention to the antiviral properties of both live and dead cells of $L A B$, this review aims to underline the significance of supporting our health with the wealth of foods that are rich in terms of their microbial diversity. Further scientific research must focus on the several technical, biological, and clinical aspects of traditional fermentations.
\end{abstract}

\section{Introduction}

Probiotics are defined as 'Live microorganisms which when administered in adequate amounts confer a health benefit on the host' (FAO/WHO, 2006). The early in vitro tests for the study of probiotic strains included resistance to gastric acidity, bile acid resistance, adherence to mucus and/or human epithelial cells and cell lines, antimicrobial activity against potentially pathogenic bacteria, ability to reduce pathogen adhesion to surfaces, bile salt hydrolase activity and resistance to spermicides (applicable to probiotics for vaginal use) (FAO/WHO, 2006). These criteria were based on the belief that probiotic strains have to survive the harsh conditions of the stomach and pass to the intestines at sufficient quantities, in order to be effective. Yet, advances in research on probiotics have shown that a probiotic organism may function at locations other than the intestines, such as the pharynx (Santagati et al., 2015) and by a wide range of mechanisms which may be by direct contact with the pathogen, or indirectly, for instance, by boosting the host's immune system. Accordingly, it was agreed that probiotic organisms (single or in combination) should provide convincing evidence regarding a certain healthbenefit by well-conducted studies in humans, including: positive meta-analyses on specific strain(s) or strain combinations on a diversity of clinical endpoints such as infectious diarrhea, antibiotic-associated diarrhea, irritable bowel syndrome and ulcerative colitis (AlFaleh et al., 2011; Allen et al., 2010; Aponte et al., 2013; Goldenberg et al., 2017; Ritchie \& Romanuk, 2012), by scientifically accepted assessment methods, wellconducted RCTs (Randomized Controlled Trials) or strong evidence from large observational studies (Hill et al., 2014). 
In general, probiotic organisms are mostly lactic acid bacteria that occur in fermented food products. Health effects of probiotics are generally at the strain level and in a dose-dependent manner. However, in some countries, such as Canada certain species of Bifidobacterium and Lactobacillus, when delivered in food at a level of $1 \times 109$ colony forming units (CFU) per serving, have been accepted as being probiotic, resulting in a strain-independent assignment of some bacteria as probiotics (Hill et al., 2014).

Despite of all the health benefits of probiotics, it is now clear that the use of probiotics is not safe for all the individuals, in particular those who are immunodeficient (Kothari et al., 2019; Wagner \& Balish, 1998). The possibility that some probiotics might become opportunistic pathogens is surely a disadvantage for the consumption of live probiotics as supplements. Hence, it is now suggested that the consumption of capsules with live probiotics should be regarded as drug consumption and should, therefore be much more strictly regulated (Kothari et al., 2019). While the safety of probiotics is being questioned, recent studies have shown that even the dead cells of probiotics might have health benefits, especially through the modulation of the immune system (Taverniti \& Guglielmetti, 2011). Since the definition of probiotics requires that cells are viable, a new term for the non-viable forms of probiotics has been proposed as the 'paraprobiotics' (Taverniti \& Guglielmetti, 2011).

The concept of paraprobiotics is important, not only because it provides a safer alternative to the use of viable microorganisms, but also because it raises the question as to how appropriate it is to define probiotics as 'live microorganisms'. It further raises the question as to the best form of probiotic consumption in terms of safety and health benefits. Namely, is it better to use high numbers of a few different viable microorganisms as in the case of capsules, or is it better to have a greater variety of different species at lower cell counts, as in the case of fermented foods, which are also likely to be rich in terms of paraprobiotics? Is it better to use commercially cultured fermented food products or traditional fermented foods that generally contain a broader range of microbial cultures, etc. (Rezac et al., 2018)? These questions need to be answered by further research.

\section{Antiviral Mechanisms}

The importance of probiotics, most being lactic acid bacteria ( $L A B)$, in both preventing and/or alleviating the symptoms or the duration of viral diseases is of growing importance (Al Kassaa, 2017). The reader is referred to excellent recent reviews on the topic (Al Kassaa et al., 2014; Kanauchi et al., 2018; Lehtoranta et al., 2014; Sousa et al., 2020; Tapiovaara et al., 2016).

Viral infections are either upper respiratory tract infections or viral gastroenteritis. Interestingly, probiotics have mechanisms that can act on both groups of viral infections. The antiviral mechanisms of probiotic LAB are summarized in Figure 1.

These mechanisms can be classified into two major categories: 1) Mechanisms related directly to the

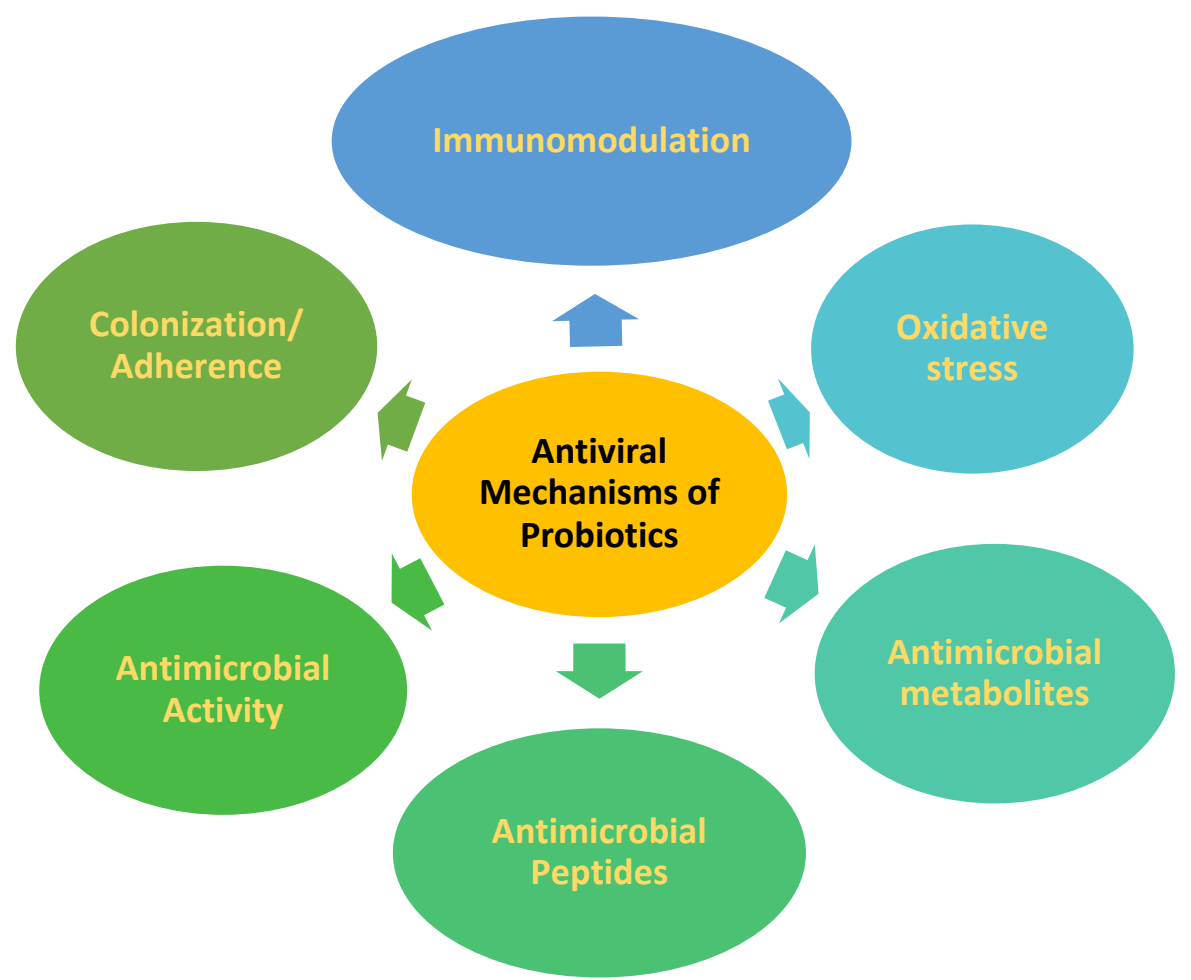

Figure 1. Summary of the various antiviral mechanisms of probiotics. 
organism itself and its cross-talk with the host and/or contact with the virus. Such probiotic LAB may originate from the food, or they may be supplemented in the form of capsules. 2) Mechanisms related to the antiviral metabolites generated in food products fermented by LAB. In such cases, although the organism might be the same, metabolites might differ due to differences in the fermented food material, such as milk, cereals, legumes, or vegetables. Based on this classification, only the first group of antiviral mechanisms will function when probiotics are consumed in the form of capsules, whereas in the case of fermented foods, both mechanisms will act together, including those related to the existence of paraprobiotics (Kanauchi et al., 2018).

Regarding the site of antiviral action of probiotic $L A B$, the intestines are often mentioned. However, research indicates that intestines are not the only site of antiviral action. The gastrointestinal (GI) tract starts at the mouth and ends at the anus. The mouth/nose is the first part of the GI that comes in contact with the environment. When probiotics are administered in the form of tablets, they pass directly to the stomach. However, when probiotic food products are consumed, there is contact with the mouth. Based on research this fact appears to be significant due to two reasons; probiotics can colonize the tonsils and the pharynx for several hours to several days, thereby exerting their actions directly at the first contact site of the GI. For example, in a study conducted by Santagati et al. (2015), nasal sprays of Streptococcus (S.) salivarius $24 \mathrm{SMBC}$ were shown to have the capability of colonizing the rhinopharynx tissues in $95 \%$ of subjects, aged $30-54$ years, and persisted in $55 \%$ of the individuals even after 6 days. In another study, where Lactobacillus ( $L b$.) plantarum DSM 9843 was administered to healthy volunteers who either gargled or drank oatmeal gruel with or without fruit juice, $L$ b. plantarum DSM 9843 was found in tonsillar scrapings 4-8 $\mathrm{h}$ after intake, suggesting an ability of these bacteria to adhere to tonsillar cells (Stjernquist-Desatnik, 2000).

Accordingly, studies indicate that the antiviral effect of probiotic LAB can be initiated in the mouth, tonsils, and the pharynx. These observations are important because they may suggest a greater advantage of probiotic food consumption in the prevention of URT viral infections as compared to probiotics intake in the form of capsules, especially regarding mechanisms that involve direct contact of the probiotic organisms with the infectious viruses before they can reach the lungs.

Among the various antiviral mechanisms, perhaps the immune boosting effect of probiotic LAB is the most important one. As opposed to bacterial infections, viruses cannot be eliminated by the use of antibiotics. Although medications target viral proteins/enzymes for inactivation, most of these medications only have limited effect in alleviating symptoms and some have side-effects. At the end of the day, the most effective antiviral mechanisms are those related to the modulation of the host's immune system. As we have all seen in the case of Covid-19, those individuals with a strong immune system could cope with the virus with almost no symptoms at all, while those, especially the elderly people, with weak immune systems ended up having very severe symptoms.

The immunomodulatory effect of probiotics, and perhaps of most lactic acid bacteria present in fermented food products, involves the following: protection of epithelial cells by stimulating the production of mucin and the secretion of mucus; biofilm formation which probably saturates the receptors, including viral receptors; activation of dendritic cells to secrete proinflammatory cytokines, such as IL-6, IL-12 and interferon (IFN) $\gamma$; boosting the innate immune cells, such as macrophages and natural killer (NK) cells that kill viruses and virus-infected cells, produce interferon IFN $\alpha$, an antiviral cytokine; stimulating the overexpression of innate immunity-related genes such as Toll-like receptors (TLR7) (Al Kassaa, 2017; PimentelNunes et al., 2010). Some of these mechanisms occur in the lungs, upon infection by respiratory viruses, while the probiotics thrive in the gut (Al Kassaa, 2017). The $L A B$ are also known to enhance the adaptive immune response, including lymphocyte proliferation and $\mathrm{GI}$ tract specific IgA production and others (Tsai et al., 2012).

Another antiviral mechanism of probiotics is related to the production bioactive peptides. These peptides can be generated either by the probiotic organism itself or generated by the enzymatic digestion of proteins that are part of the food source; the latter is relevant to all lactic acid bacteria that have the capability of digesting food proteins with proteases.

Bioactive peptides are functional peptides consisting of small peptide sequences, such as 2-20 amino acid residues, that have important roles in human health (Hartmann \& Meisel, 2007). Although milk and dairy products are rich food sources in terms of bioactive peptides, these peptides are also found in most plants, various meat types, and eggs (Korhonen \& Pihlanto, 2006; Pihlanto \& Korhonen, 2015). These peptides originate from the hydrolysis of the native proteins of the food source, and have been revealed to have functional properties such as opioid, mineralbinding, immunomodulatory, antimicrobial, antioxidant, antithrombotic, hypocholesterolemic, anticarcinogenic, etc. (Korhonen \& Pihlanto, 2006; McClements et al., 2009; Meisel, 2005). They are either formed by the activity of their native enzymes or by microbial proteolytic enzymes. Especially in fermented foods, proteolytic enzymes belonging to starter cultures or natural microbiota are responsible for the formation of bioactive peptides (Michaelidou, 2008; Szwajkowska et al., 2011). Bioactive peptides with different lengths of amino acids were obtained by the activity of bacterial peptidases and proteases (Ardö et al., 2017). Moreover, intracellular enzymes that are released as a result of autolysis of dead bacterial cells may also play a role in 
the formation of bioactive peptides (Fan et al., 2019; Jensen et al., 2009; Solieri et al., 2018). The latter example suggests that the concept of paraprobiotics may be significant in fermented food products, particularly for those products undergoing storage in brine or those kept under long periods of storage for ripening, etc.

Although most studies on the functional properties of bioactive peptides in fermented products have focused on antibacterial peptides, there are some studies on the antiviral properties of both proteins in some foods and peptides formed by their enzymatic hydrolysis. Mandal et al. (2016) have informed that bioactive peptides generally bind to cell receptors of host, inhibiting the attachment of viruses. Bioactive peptides produced by the enzymatic activities of probiotics can also show the antiviral effect by directly binding to virus particles. Furthermore, bacteriocins, which are peptides synthesized in the ribosomes of bacteria, can have antiviral effects by aggregating of virus particles, blocking the receptor sites where viruses are attached in the host cell, or inhibiting key reactions in the replication cycle of viruses (Todorov et al., 2010; Wachsman et al., 2003).

Among the various metabolites of probiotics, hydrogen peroxide and lactic acid produced by Lactobacillus species were shown to play an important role in their antiviral effects. Conti et al. (2009) suggested that lactic acid and $\mathrm{H}_{2} \mathrm{O}_{2}$ could be responsible for reducing intracellular events of herpes simplex virus type 2 multiplication. Acidic $\mathrm{pH} \leq 4.5$, which occurs due to lactic acid production, disrupts herpes simplex virus type 2 and leads to a reduction in attachment and invasion of this virus (Tuyama et al., 2006). In addition, exopolysaccharides (EPS) produced by probiotic bacteria have been reported to have antiviral effects in several studies (Arena et al., 2006; Kanmani et al., 2018; Kim et al., 2018). The EPS are known to stimulate immunologic system, to prevent the absorption and penetration of viruses into host cell, and to inhibit various retroviral reverse transcriptase (Arena et al., 2006; Saadat et al., 2019). EPS produced by $L b$. delbrueckii OLL1073R-1 stimulated type I interferon production (Kanmani et al., 2018). Also, EPS of $L b$. plantarum LRCC310 were presented to have an inhibition effect against human rotavirus Wa strain in vitro and they also were found to decrease the rotavirus infection in mice models (Kim et al., 2018).

\section{Antiviral Probiotic Lactic Acid Bacteria}

Lactic acid bacteria (LAB) or probiotics can inhibit viruses in a variety of ways. These include direct physical interaction between viruses and bacteria, stimulation of the host's immune system, and the production of antiviral substances with or without protein structure (Al Kassaa et al., 2014). Direct interactions prevent adsorption of the virus into cells. In some experimental observations, it has been reported that various probiotic bacteria inhibit some viruses by direct binding (Al Kassaa et al., 2014; Botić et al., 2007; Z. Wang et al., 2013). Direct interactions between vesicular stomatitis virus and probiotic bacteria including Bifidobacterium (B.) breve DSM 20091, B. longum Q 46, Lb. reuteri DSM 12246, Lb. plantarum M1.1, Lb. paracasei $\mathrm{F} 19$, Lb. paracasei $\mathrm{A} 14$, and Lb. paracasei/rhamnosus $\mathrm{Q} 85$ (Botić et al., 2007), between influenza viruses and Enterococcus (E.) faecium NCIMB 10415 (Z. Wang et al., 2013), and herpes simplex type 2 and $L b$. gasseri CMUL57 (Al Kassaa et al., 2014) have been observed.

The substances such as lipoteichoic acid, peptidoglycan, nucleic acids, and muramyl dipeptide found in probiotics have a stimulating effect on the immune system (Pimentel-Nunes et al., 2010). Probiotic bacteria stimulate immune system by regulating $T$ cells, lymphoid cells, and Thelper 17 cells by the recognition of probiotics themselves or their metabolic products (Kanauchi et al., 2018). It has been suggested that the great majority of probiotic bacteria show inhibitory activity against most important respiratory viruses with their immunomodulatory systems (Lehtoranta et al., 2014). Since these viruses attach to mucosal cells in the respiratory tract, probiotics and their antimicrobial agents cannot physically interact with the virus (Al Kassaa, 2017). Therefore, probiotics eliminate these viruses by stimulating the host's immune system. Therefore, these microorganisms are also called immunobiotics (Kitazawa et al., 2013).

Probiotic LAB and upper respiratory tract viruses

Among the probiotics, the antiviral effect of Lactobacilli against respiratory viruses is most widely examined. Fermented milk product containing $L b$. casei DN-114 001 strain has been reported to reduce respiratory infections by causing an increase in neutrophil, leukocyte, and natural killer cell counts in humans (Guillemard et al., 2010). Moreover, yogurts fermented with $L b$. delbrueckii subsp. bulgaricus OLL1073R-1 improved natural killer cell activity in elderly individuals (Makino et al., 2010). In a study performed on mice, $L b$. plantarum L-137 strain was observed to increase T-helper-1 (Th1) production against influenza virus (H1N1) (Maeda et al., 2009). It was also determined that $L b$. plantarum $Y U$ strain suppressed the proliferation of the H1N1 virus in the lungs of the mice by increasing the Th1 immune response (Kawashima et al., 2011).

In general, it appears that IFN- $\alpha$ takes a crucial role in the antiviral immune response by triggering the cytotoxic activity of NK cells (Kanauchi et al., 2018). For example, $L b$. acidophilus L-92 antiviral activity against influenza A/PR/8/34 (H1N1) virus occurred by increasing NK cell and the production of IFN- $\alpha$ in a mouse model (Goto et al., 2013). Lb. rhamnosus Lr05 and Lr06 strains provided a protective effect against human respiratory virus strain $A 2$ by stimulating the production of interferon (IFN)- $\alpha$, IFN- $\beta$, and interleukin (IL)- 6 (Tomosada et al., 2013). In another study on mice 
model, Lb. brevis KB-290 also presented inhibition activity towards influenza $A / P R / 8 / 34$ virus by stimulating immunoglobulin A (IgA) and IFN- $\alpha$ (Waki et al., 2014). Lactococcus lactis JCM 5805 strain inactivated influenza $A / P R / 8 / 34$ virus by generating high amounts of IFN- $\alpha$ in human (Sugimura et al., 2015). Lb. gasseri TMC0356 reduced influenza A/PR/8/34 symptoms in experimental mice by improving the secretion of IgA, IFN- $\gamma$, IL-12, and IL- 6 (Kawase et al., 2010). Lb. pentosus S-PT84 strain inhibited influenza $\mathrm{A} / \mathrm{PR} / 8 / 34$ virus by activating lung $\mathrm{NK}$ cells and modulating the Th1/Th2 balance (Izumo et al., 2010). On the other side, $L b$. fermentum $\mathrm{CJL}-112$ strain augmented IL-2 and IFN- $\gamma$ cytokines against influenza A/NWS/33 (H1N1) virus (Yeo et al., 2014).

Studies on Bifidobacteria have shown immunomodulation similar to those of Lactobacilli. $B$. longum stimulated the production of interleukins (IL) and IFN cytokines against influenza $A / P R / 8 / 34$ virus (Iwabuchi et al., 2011). B. animalis subsp. lactis Bb12 in breastfed infants was found to increase anti-poliovirus specific IgA, but not anti-rotavirus specific IgA (Holscher et al., 2012). Various probiotic strains can be used in combination to provide a more effective antiviral property.

\section{Probiotic LAB and gastrointestinal viruses}

It is known that probiotics decline the duration of diarrhea caused by rotavirus. Probiotic application has been revealed to be more effective at the beginning of the diarrheal stage (Rosenfeldt et al., 2002). Probiotic $B$. longum and $L b$. acidophilus strains showed antiviral activity against rotavirus in vitro and they reduced the duration of diarrhea in pediatric patients (Lee et al., 2015). In addition to this, it was determined that the duration of rotavirus diarrhea decreased as a result of giving the solution containing probiotic $L b$. acidophilus, Lb. rhamnosus, B. longum and Saccharomyces boulardii strains orally to children under 2 years of age (Grandy et al., 2010). Similarly, Lb. rhamnosus 19070-2 and $L b$. reuteri DSM 12246 reduced length of hospital stay based on diarrhea (Rosenfeldt et al., 2002).

Cell-free supernatants of yogurt containing $L b$. acidophilus, $L b$. rhamnosus, $L b$. plantarum, $S$. thermophilus and $B$. bifidum was found to be more effective than that of MRS broth containing these strains against enteroviruses (Choi et al., 2009). This inhibitory effect probably occurred due to antiviral substances produced by bacterial cells. Considering the result of this study, the intake of probiotics with foods may be more advantageous than taking them in capsules or tablets.

\section{Antiviral proteinaceous compounds produced by probiotic LAB}

Bacteriocins are antibacterial peptides synthesized by bacteria in their ribosome (Todorov et al., 2010). Al Kassaa et al. (2014) have been asserted that some bacteriocins have both antibacterial and antiviral properties. Various bacteria including probiotics can produce such antiviral peptides. In published studies, subtilosin bacteriocin of Bacillus amyloliquefaciens, bacteriocin of $L b$. delbrueckii, TVAAPSVFIFPPSDEQLK and EAKVQWKVDNALQSGNSQESVTEQDSKDSTYSLSSTLTLSK bacteriocins of Bacillus subtilis, bacteriocin of $L b$. bulgaricus $761 \mathrm{~N}$, bacteriocin of E. mundtii ST4V, pediocin-like bacteriocin of $E$. faecium and enterocin AAR-71 of E. faecalis AAR-71 showed both antibacterial and antiviral activities (Al Kassaa et al., 2014; Todorov et al., 2005, 2010; Torres et al., 2013). Yang et al. (2017) have also reported that the metabolic products containing peptides of probiotic $L b$. plantarum N4 strain have antiviral effects. The metabolic products, including acids, alcohols, peptides, esters, ketones, phenols, of probiotic $L$ b. plantarum N4 strain, has been found to be effective against gastroenteritis coronavirus (Yang et al., 2017). A pediocin-like bacteriocin produced by $E$. faecium ST5Ha strain has been reported to possess antiviral effect against HSV-1 (Todorov et al., 2010). The $\mathrm{EC}_{50}$ value of this bacteriocin against HSV-1 was found to be $50 \mu \mathrm{g} / \mathrm{mL}$. It was determined that extracellular extracts, possibly including bacteriocins, of $L b$. bulgaricus $761 \mathrm{~N}$ strain showed antiviral activity against hepatitis C virus (HCV) (El-Adawi et al., 2015). Lb. delbrueckii subsp. bulgaricus 1043 was shown to be effective on influenza virus (Serkedjieva et al., 2000). As for bacteriocin of $E$. mundtii, it has inactivated herpes simplex viruses ( 1 and 2 ), a polio virus, and a measles virus depending on its dose (Todorov et al., 2005). The highest inhibition of this bacteriocin was found to show at a concentration of $400 \mu \mathrm{g} / \mathrm{mL}$.

The antiviral actions of the various peptides derived by fermentations have been analysed. In a study on casein-derived peptides, although positively or negatively charged peptides from $\alpha_{s 2^{-}}, \beta$ - and $\kappa$-caseins had no antiviral effects (Floris et al., 2003), lactoferrin, a protein naturally found in milk, has been reported to have both antibacterial and antiviral properties (Farnaud \& Evans, 2003; Pan et al., 2007). Additionally, ADRDQYELL and EDLIWK peptides produced by the enzymatic hydrolysis of lactoferrin showed antiviral properties (Dziuba et al., 2009).

Lactoferrin and lactoferrin derived peptides were also shown to present antiviral activity against HIV-1, poliovirus, rotavirus, herpes simplex virus, hepatitis $C, G$, and $B$ viruses, and cytomegalovirus by increasing the immunological reactions in the host (Farnaud \& Evans, 2003; Pan et al., 2007; Szwajkowska et al., 2011). Lactoferrin-derived ADRDQYELL and EDLIWK peptides have been revealed to show antiviral activity against herpes simplex virus type 1 (HSV1) (Siciliano et al., 1999). Additionally, K-casein-derived glycomacropeptide and lactoferrin, which are originated from milk, have been reported to show activity against influenza virus (Kawasaki et al., 1993). These researchers attributed the inhibitory activity to sialic acids in glycomacropeptide and lactoferrin. 
Immunomodulatory peptides can also act as antiviral agents because they regulate or improve immune responses. These biological active peptides have been identified in various fermented foods such as yogurt, cheese, fermented milk products (Fan et al., 2019; Jin et al., 2016; Pisanu et al., 2015; Tonolo et al., 2020). Pisanu et al. (2015) reported the presence of immunomodulator peptides in sheep cheese including YQEPVLGPVRGPFPI, QEPVLGPVRGPFPIL, YQEPVLGPVRGPFP, QEPVLGPVRGPFPI QEPVLGPVRGPFP, QEPVLGPVRGPF, PVLGPVRGPFPIL, PVLGPVRGPFP, EPVLGPVRGPFPI, EPVLGPVRGPFP, EPVLGPVR, LGPVRGPFPI, GPVRGPFP, GPVRGPF, DMPIQAFLLYQEPVLGPVR peptides from the $C$ terminal region of the $\beta$-casein and immunomodulator LNENLLR, VLNENLLR, LNENLLRF peptides from the $N$ terminal region of the $\alpha_{s 1}$-casein. Besides, immunomodulator $\alpha_{s 1^{-}}$ casein derived peptide LNENLLRF and $\beta$-casein derived peptides GPVRGPFPI, EPVLGPVRGPFP, QEPVLGPVRGPFP, YQEPVLGPVRGPFP were determined in milk casein fermented by $L b$. helveticus $\mathrm{CICC6024}$. The $\alpha_{s 1}$-casein derived isracidin peptide (RPKHPIKHQGLPQEVLNENLLRF) is known to be an immunomodulating peptide. This peptide has been found in fermented milk products such as yogurt and cheese (Fontenele et al., 2017; Gagnaire et al., 2011; Jin et al., 2016). Therefore, fermented milk products appear to be a good source to benefit from these peptides.

\section{Paraprobiotics}

Observations on the health benefits of non-viable cells of probiotics has raised attention to a new concept of utilizing dead cells (paraprobiotics), instead of viable cells, as mentioned above. Results of studies comparing the efficacy of paraprobiotics and probiotics on the immune system are contradictory. Some studies have reported that living cells provide a stronger immune response as compared to dead cells (Cross et al., 2004; Haller et al., 2000). In contrast, some authors have asserted that the immuno-stimulatory effects of living and dead cells were similar (Lopez et al., 2008; Ryan et al., 2008). These differences may have occurred depending on the strain type and inactivation method used (Taverniti \& Guglielmetti, 2011). In this context, more detailed studies comparing different strains and different inactivation methods are needed. Besides, the interaction of different strains and inactivation methods can be examined.

\section{Fermented Food Products and The Rising Awareness on The Importance of Food Microbiodiversity}

In October 2013, an expert panel was convened by the International Scientific Association for Probiotics and Prebiotics (ISAPP) to discuss the field of probiotics. Based on their proposal, there is evidence that supports the beneficial relationship between some foods containing live microbes, especially fermented dairy products, and reduced risk of certain diseases, such as type 2 diabetes (Hill et al., 2014). For example, one study conducted on >6,500 individuals found (SoedamahMuthu et al., 2013) that yogurt consumers had reduced levels of circulating triglycerides and glucose, as well as reduced systolic blood pressure and insulin resistance, compared with non-consumers (H. Wang et al., 2013). However, the panel's judgement was towards excluding such food products from the list of probiotics and rather using the term 'live and active cultures' instead of 'probiotics'. This judgement was based on the fact that although such fermented food products might potentially have beneficial microbes, these cultures often represent a diverse community that is not welldefined in terms of strain composition and stability (Hill et al., 2014).

Traditional fermented foods are rich in terms of 'live and active cultures'. In other words, there are several different microbial species surviving together in the same environment (Dimidi et al., 2019). As compared to fermented foods produced from commercial probiotic and starter cultures, traditional fermented foods offer an extremely high microbial diversity. This microbiodiversity of natural fermented foods is valuable, considering that most probiotics are Lactobacilli that originate from these natural food environments. Thus, having a higher number of microbial species increases the likelihood of having microorganisms and biochemical reactions with health benefits. As the diversity of lactic acid bacteria increases, it can be suggested that the variety of antiviral as well as antibacterial and health promoting effects are likely to increase, although this has yet to be experimentally proven.

Fermented foods have been part of the Turkish Tradition for thousands of years. The Word 'Yogurt' is Turkish and is first mentioned in Divanü Lügati't-Türk written by Kaşgarlı Mahmut in the 10th century and by Balasagunlu Yusuf Hac Hacip in Kutadgu Bilig. Traditionally yogurt is used in healing food poisoning, diarrhea, and as an anti-toxin, in general. In Turkey, yogurt is industrially produced by $S$. thermophilus and Lactobacillus delbrueckii spp. bulgaricus cultures. However, still many people produce yogurt at home by traditional methods.

Kefir is another fermented dairy product frequently produced at home. Not only fermented milk products but also fermented vegetables are an important part of the Turkish traditional kitchen. For example, pickles from vegetables are routinely made at homes, allowing food preservation. Olives are also part of the widespread fermentation tradition.

The Turkish consumer believes that home made fermented foods are much healthier than the industrially produced ones. Although this is not strictly correct in terms of food hygiene, it is probably correct from a probiotic point-of-view. Although traditional fermented foods do not have a well-defined and standard microbial population, in general, all are rich in terms of their microbiodiversity. For example, for the 
production of yogurt, milk is fermented with chickpea or by using herbs such as Galium aparine (Yogurt otu) etc. When yogurt is made in this traditional manner, namely by starting from natural resources of bacteria, the resulting yogurt consists of different bacterial species and is not limited by the two cultures, $S$. thermophilus and $L b$. bulgaricus, described by the Turkish Food Codex (2009). In one study, Çebi and Aydın (2019) analysed lactic acid bacteria from fermented chickpea. Accordingly, Lactoccoccus lactis subsp. lactis was found as the dominant species $(90 \%)$, followed by $L b$. plantarum (6.7\%) and $L b$. brevis (3.3\%). It was concluded that the natural microflora of chickpea was suitable for use in the preparation of sourdough. In another study, Hancıoğlu-Sıkılı (2003) isolated Lb. plantarum, Lb. pentosus, Lb. sanfrancisco, E. mundtii, E. gallinarum, Pediococcus (P.) urinae-equi, $L b$. viridencens, and $S$. thermophilus species and Saccharomyces cerevisiae from chickpea. Studies on another popular Turkish fermented food product, namely Tarhana, has shown that the bacterial population consisted of $P$. acidilactici (27\%), S. thermophilus (19\%), Lb. fermentum (19\%), E. faecium (12\%), P. pentosaceus (7\%), Leuconostoc pseudomesenteroides (5\%), Weissella cibaria (4\%), 2\% each of $L b$. plantarum, Lb. delbrueckii spp. bulgaricus, Leuconostoc citreum, $1 \%$ as $L$ b. paraplantarum and $0.5 \%$ Lb. casei (Sengun et al., 2009). Kefir is yet another highly popular fermented dairy product in Turkey. Various studies have been conducted on the identification of microorganisms from kefir grains by culture-dependent and culture-independent techniques (Demir, 2020; Dertli \& Çon, 2017; Kesmen \& Kacmaz, 2011; Nalbantoglu et al., 2014; Purutoğlu et al., 2020; Taş et al., 2012). Dertli and Çon (2017) identified 15 different bacterial species and 17 yeast and mold species from kefir grains by culture-independent method and $L b$. kefiranofaciens was found to be the dominant kefir associated bacterial strain. On the other hand, Purutoğlu et al. (2020) identified lactic acid bacteria and yeast from kefir grains by culture-dependent method and they have revealed that Lactococcus lactis strains were dominant among them. Moreover, Kesmen and Kacmaz (2011) determined Lactococcus lactis, Leuconostoc mesenteroides and $L b$. kefiri as dominant strains in kefir grains analysed in culturedependent method, while $L b$. kefiranofaciens was dominant strain in culture-independent method.

It is possible to continue giving further examples, however, the message is already very clear; Considering the antiviral mechanisms, namely immunomodulation, antiviral metabolites, peptides, adherence and others, traditional fermented foods are surely more likely to provide health benefits due to their high microbial diversity, as compared to the commercial industrial products which are produced by a limited number of well-defined probiotic or starter cultures. Although it may not be possible to use the word 'probiotic' without providing proof by clinical trials, a high microbiodiversity, specifically of Lactobacilli increase the likelihood of providing several health benefits. These comparisons await further experimental analysis.

\section{Conclusion}

Both probiotic cultures and their metabolites in fermented foods have been proven to have antiviral activity both against upper respiratory tract and gastrointestinal viral infections. Among the antiviral mechanisms, most important ones appear to be their capability of modulating immune response, the production of antiviral metabolites and direct interaction of cells and the virus particles. Probiotics, when orally administered or introduced by nasal spraying, have been shown to thrive in the mouth and the nasopharynx and tonsils up to several days. This suggests, consumption of food is advantageous by initiating antiviral action from the beginning of the Gl. Not only viable cells but non-viable probiotic cells (paraprobiotics) have also been shown to have health benefits, including antiviral action. Paraprobiotics provide a safer alternative to the administration of live probiotics at high numbers. Such dead cells naturally occur in fermented foods, especially upon long periods of storage and ripening. By being a natural source of paraprobiotics, diverse microbial species, mostly Lactobacilli, and rich metabolites, traditional fermented food products may be the hidden treasure of biological health benefits, including antiviral activity but this yet to be supported by experimental evidences.

\section{Future Trends and Perspectives}

There have been a vast number of publications up to date on the health benefits of probiotic lactic acid bacteria (LAB), including their antiviral activities, however, these mechanisms are far from being fully understood. The complex interrelationship of multiple mechanisms arising from the presence of single or combinations of $L A B$, viable or dead cells, consumption of $L A B$ in the form of tablets or as part of fermented foods etc., influences the final cross-talk of bacterial and host cells, as well as bacterial and viral interactions and the presence/absence and action of viral antagonistic chemicals. The enormous variety of viruses both respiratory and gastrointestinal makes the whole story even more complicated. The complex interplay of these biological and biochemical components requires further dedicated research for a clearer understanding of these antiviral mechanisms. In the literature, in situ studies with the antiviral properties of fermented food metabolites, including peptides are inadequate and should also be considered in future studies. Besides all aforementioned viruses in the previous studies, the antiviral effects of peptides on Covid-19, which is the most troublesome virus of today, can be examined. Finally, clinical tests analyzing the antiviral and other health benefits of traditional food products with a rich 
variety of $L A B$ are few, if any, in the literature, and should be of concern in future studies.

\section{References}

Al Kassaa, I. (2017). Antiviral Probiotics: A New Concept in Medical Sciences. In New Insights on Antiviral Probiotics (pp. 1-46): Springer.

Al Kassaa, I., Hamze, M., Hober, D., Chihib, N.-E., \& Drider, D. (2014). Identification of vaginal lactobacilli with potential probiotic properties isolated from women in North Lebanon. Microbial Ecology, 67(3), 722-734.

Al Kassaa, I., Hober, D., Hamze, M., Chihib, N. E., \& Drider, D. (2014). Antiviral potential of lactic acid bacteria and their bacteriocins. Probiotics and Antimicrobial Proteins, 6(34), 177-185.

AlFaleh, K., Anabrees, J., Bassler, D., \& Al-Kharfi, T. (2011). Probiotics for prevention of necrotizing enterocolitis in preterm infants: John Wiley \& Sons.

Allen, S. J., Martinez, E. G., Gregorio, G. V., \& Dans, L. F. (2010). Probiotics for treating acute infectious diarrhoea: John Wiley \& Sons.

Aponte, G. B., Mancilla, C. A. B., Carreazo, N. Y., Galarza, R. A. R., \& Group, C. I. D. (2013). Probiotics for treating persistent diarrhoea in children. The Cochrane Database of Systematic Reviews, (8), 1-18.

Ardö, Y., McSweeney, P. L., Magboul, A. A., Upadhyay, V. K., \& Fox, P. F. (2017). Biochemistry of cheese ripening: proteolysis. In Cheese (pp. 445-482): Elsevier.

Arena, A., Maugeri, T. L., Pavone, B., Iannello, D., Gugliandolo, C., \& Bisignano, G. (2006). Antiviral and immunoregulatory effect of a novel exopolysaccharide from a marine thermotolerant Bacillus licheniformis. International Immunopharmacology, 6(1), 8-13.

Botić, T., Dan $\varnothing$, T., Weingartl, H., \& Cencič, A. (2007). A novel eukaryotic cell culture model to study antiviral activity of potential probiotic bacteria. International Journal of Food Microbiology, 115(2), 227-234.

Choi, H.-J., Song, J.-H., Ahn, Y.-J., Baek, S.-H., \& Kwon, D.-H. (2009). Antiviral activities of cell-free supernatants of yogurts metabolites against some RNA viruses. European Food Research and Technology, 228(6), 945950.

Codex, T. F. (2009). Communiqué of Fermented Milk In. Ankara, Turkey: Official Gazette.

Conti, C., Malacrino, C., \& Mastromarino, P. (2009). Inhibition of herpes simplex virus type 2 by vaginal lactobacilli. Journal of Physiology and Pharmacology, 60(Suppl 6), 19-26.

Cross, M. L., Ganner, A., Teilab, D., \& Fray, L. M. (2004). Patterns of cytokine induction by gram-positive and gram-negative probiotic bacteria. FEMS Immunology \& Medical Microbiology, 42(2), 173-180.

Çebi, K., \& Aydın, F. (2019). Isolation and identification of lactic acid bacteria from chickpea leaven traditionally produced in laboratory. Black Sea Journal of Agriculture, 2(2), 79-85.

Demir, H. (2020). Comparison of traditional and commercial kefir microorganism compositions and inhibitory effects on certain pathogens. International Journal of Food Properties, 23(1), 375-386.

Dertli, E., \& Çon, A. H. (2017). Microbial diversity of traditional kefir grains and their role on kefir aroma. LWT-Food Science and Technology, 85, 151-157.
Dimidi, E., Cox, S. R., Rossi, M., \& Whelan, K. (2019). Fermented Foods: Definitions and characteristics, impact on the gut microbiota and effects on gastrointestinal health and disease. Nutrients, 11(8), 1806.

Dziuba, M., Dziuba, B., \& Iwaniak, A. (2009). Milk proteins as precursors of bioactive peptides. Acta Scientiarum Polonorum Technologia Alimentaria, 8(1), 71-90.

El-Adawi, H., Nour, I., Fattouh, F., \& El-Deeb, N. (2015). Investigation of the antiviral bioactivity of Lactobacillus bulgaricus $761 \mathrm{~N}$ extracellular extract against hepatitis $C$ virus (HCV). International Journal of Pharmaceutics, 11, 19-26.

Fan, M., Guo, T., Li, W., Chen, J., Li, F., Wang, C., Shi, Y., Xi-an Li, D. \& Zhang, S. (2019). Isolation and identification of novel casein-derived bioactive peptides and potential functions in fermented casein with Lactobacillus helveticus. Food Science and Human Wellness, 8(2), 156176.

FAO/WHO. (2006). Probiotics in food: Health and nutritional properties and guidelines for evaluation. Rome: Food and Agriculture Organization/World Health Organization.

Farnaud, S., \& Evans, R. W. (2003). Lactoferrin-a multifunctional protein with antimicrobial properties. Molecular Immunology, 40(7), 395-405.

Floris, R., Recio, I., Berkhout, B., \& Visser, S. (2003). Antibacterial and antiviral effects of milk proteins and derivatives thereof. Current Pharmaceutical Design, 9(16), 1257-1275.

Fontenele, M. A., do SR Bastos, M., dos Santos, K. M., Bemquerer, M. P., \& do Egito, A. S. (2017). Peptide profile of Coalho cheese: A contribution for Protected Designation of Origin (PDO). Food Chemistry, 219, 382390.

Gagnaire, V., Carpino, S., Pediliggieri, C., Jardin, J., Lortal, S., \& Licitra, G. (2011). Uncommonly thorough hydrolysis of peptides during ripening of Ragusano cheese revealed by tandem mass spectrometry. Journal of Agricultural and Food chemistry, 59(23), 12443-12452.

Goldenberg, J. Z., Yap, C., Lytvyn, L., Lo, C. K. F., Beardsley, J., Mertz, D., \& Johnston, B. C. (2017). Probiotics for the prevention of Clostridium difficile-associated diarrhea in adults and children: John Wiley \& Sons,.

Goto, H., Sagitani, A., Ashida, N., Kato, S., Hirota, T., Shinoda, T., \& Yamamoto, N. (2013). Anti-influenza virus effects of both live and non-live Lactobacillus acidophilus L-92 accompanied by the activation of innate immunity. British Journal of Nutrition, 110(10), 1810-1818.

Grandy, G., Medina, M., Soria, R., Terán, C. G., \& Araya, M. (2010). Probiotics in the treatment of acute rotavirus diarrhoea. A randomized, double-blind, controlled trial using two different probiotic preparations in Bolivian children. BMC Infectious Diseases, 10(1), 253.

Guillemard, E., Tanguy, J., Flavigny, A. L., de la Motte, S., \& Schrezenmeir, J. (2010). Effects of consumption of a fermented dairy product containing the probiotic Lactobacillus casei DN-114 001 on common respiratory and gastrointestinal infections in shift workers in a randomized controlled trial. Journal of the American College of Nutrition, 29(5), 455-468.

Haller, D., Bode, C., Hammes, W., Pfeifer, A., Schiffrin, E., \& Blum, S. (2000). Non-pathogenic bacteria elicit a differential cytokine response by intestinal epithelial cell/leucocyte co-cultures. Gut, 47(1), 79-87. 
Hancıoğlu-Sıkılı, O. (2003). Nohut mayasının mikrobiyolojik ve lezzet karakteristiklerinin arastırılması [Investigation of microbiological and flavour characteristics of chickpea sweet dough]. PhD thesis. Ege University, Izmir, Turkey, p 203.

Hartmann, R., \& Meisel, H. (2007). Food-derived peptides with biological activity: from research to food applications. Current Opinion in Biotechnology, 18(2), 163-169.

Hill, C., Guarner, F., Reid, G., Gibson, G. R., Merenstein, D. J., Pot, B., Morelli, L., Canani, R. B., Flint, H. J., Salminen, S., Calder, P. C., \& Sanders, M. E. (2014). The International Scientific Association for Probiotics and Prebiotics consensus statement on the scope and appropriate use of the term probiotic. Nature Reviews Gastroenterology \& Hepatology, 11(8), 506-514.

Holscher, H. D., Czerkies, L. A., Cekola, P., Litov, R., Benbow, M., Santema, S., Alexander, D. D., Perez, V., Sun, S., Saavedra, J. M. \& Tappenden, K. A. (2012). Bifidobacterium lactis Bb12 enhances intestinal antibody response in formula-fed infants: a randomized, doubleblind, controlled trial. Journal of Parenteral and Enteral Nutrition, 36, 106S-117S.

Iwabuchi, N., Xiao, J.-Z., Yaeshima, T., \& Iwatsuki, K. (2011). Oral administration of Bifidobacterium longum ameliorates influenza virus infection in mice. Biological and Pharmaceutical Bulletin, 34(8), 1352-1355.

Izumo, T., Maekawa, T., Ida, M., Noguchi, A., Kitagawa, Y., Shibata, H., Yasui, H. \& Kiso, Y. (2010). Effect of intranasal administration of Lactobacillus pentosus SPT84 on influenza virus infection in mice. International Immunopharmacology, 10(9), 1101-1106.

Jensen, M. P., Vogensen, F. K., \& Ardö, Y. (2009). Variation in caseinolytic properties of six cheese related Lactobacillus helveticus strains. International dairy journal, 19(11), 661-668.

Jin, Y., Yu, Y., Qi, Y., Wang, F., Yan, J., \& Zou, H. (2016). Peptide profiling and the bioactivity character of yogurt in the simulated gastrointestinal digestion. Journal of Proteomics, 141, 24-46.

Kanauchi, O., Andoh, A., AbuBakar, S., \& Yamamoto, N. (2018). Probiotics and paraprobiotics in viral infection: clinical application and effects on the innate and acquired immune systems. Current Pharmaceutical Design, 24(6), 710-717.

Kanmani, P., Albarracin, L., Kobayashi, H., lida, H., Komatsu, R., Kober, A. H., Ikeda-Ohtsuba, W., Suda, Y., Aso, H., Makino, S., Kano, H., Saito, T., Villena, J., \& Kitazawa, H. (2018). Exopolysaccharides from Lactobacillus delbrueckii OLL1073R-1 modulate innate antiviral immune response in porcine intestinal epithelial cells. Molecular Immunology, 93, 253-265.

Kawasaki, Y., Isoda, H., Shinmoto, H., Tanimoto, M., Dosako, S. i., Idota, T., \& Nakajima, I. (1993). Inhibition by k-casein glycomacropeptide and lactoferrin of influenza virus hemagglutination. Bioscience, Biotechnology, and Biochemistry, 57(7), 1214-1215.

Kawase, M., He, F., Kubota, A., Harata, G., \& Hiramatsu, M. (2010). Oral administration of lactobacilli from human intestinal tract protects mice against influenza virus infection. Letters in Applied Microbiology, 51(1), 6-10.

Kawashima, T., Hayashi, K., Kosaka, A., Kawashima, M., Igarashi, T., Tsutsui, H., Tsuji, N. M., Nishimura I., Hayashi, T., Obata, A. (2011). Lactobacillus plantarum strain YU from fermented foods activates Th1 and protective immune responses. International Immunopharmacology, 11(12), 2017-2024.

Kesmen, Z., \& Kacmaz, N. (2011). Determination of lactic microflora of kefir grains and kefir beverage by using culture-dependent and culture-independent methods. Journal of Food Science, 76(5), M276-M283.

Kim, K., Lee, G., Thanh, H. D., Kim, J.-H., Konkit, M., Yoon, S., Park, M., Yang, S., Park, E., Kim, W. (2018). Exopolysaccharide from Lactobacillus plantarum LRCC5310 offers protection against rotavirus-induced diarrhea and regulates inflammatory response. Journal of Dairy Science, 101(7), 5702-5712.

Kitazawa, H., Villena, J., \& Alvarez, S. (2013). Probiotics: immunobiotics and immunogenics: CRC Press.

Korhonen, H., \& Pihlanto, A. (2006). Bioactive peptides: production and functionality. International Dairy Journal, 16(9), 945-960.

Kothari, D., Patel, S., \& Kim, S.-K. (2019). Probiotic supplements might not be universally-effective and safe: A review. Biomedicine \& Pharmacotherapy, 111, 537547.

Lee, D. K., Park, J. E., Kim, M. J., Seo, J. G., Lee, J. H., \& Ha, N. J. (2015). Probiotic bacteria, B. longum and L. acidophilus inhibit infection by rotavirus in vitro and decrease the duration of diarrhea in pediatric patients. Clinics and Research in Hepatology and Gastroenterology, 39(2), 237-244.

Lehtoranta, L., Pitkäranta, A., \& Korpela, R. (2014). Probiotics in respiratory virus infections. European Journal of Clinical Microbiology \& Infectious Diseases, 33(8), 12891302.

Lopez, M., Li, N., Kataria, J., Russell, M., \& Neu, J. (2008). Live and ultraviolet-inactivated Lactobacillus rhamnosus GG decrease flagellin-induced interleukin-8 production in Caco-2 cells. The Journal of Nutrition, 138(11), 22642268.

Maeda, N., Nakamura, R., Hirose, Y., Murosaki, S., Yamamoto, Y., Kase, T., \& Yoshikai, Y. (2009). Oral administration of heat-killed Lactobacillus plantarum L-137 enhances protection against influenza virus infection by stimulation of type I interferon production in mice. International Immunopharmacology, 9(9), 1122-1125.

Makino, S., Ikegami, S., Kume, A., Horiuchi, H., Sasaki, H., \& Orii, N. (2010). Reducing the risk of infection in the elderly by dietary intake of yoghurt fermented with Lactobacillus delbrueckii ssp. bulgaricus OLL1073R-1. British Journal of Nutrition, 104(7), 998-1006.

Mandal, S. M., Pati, B. R., Chakraborty, R., \& Franco, O. L. (2016). New insights into the bioactivity of peptides from probiotics. Frontiers in Bioscience, 8, 450-459.

McClements, D. J., Decker, E. A., Park, Y., \& Weiss, J. (2009). Structural design principles for delivery of bioactive components in nutraceuticals and functional foods. Critical Reviews in Food Science and Nutrition, 49(6), 577-606.

Meisel, H. (2005). Biochemical properties of peptides encrypted in bovine milk proteins. Current Medicinal Chemistry, 12(16), 1905-1919.

Michaelidou, A. M. (2008). Factors influencing nutritional and health profile of milk and milk products. Small Ruminant Research, 79(1), 42-50.

Nalbantoglu, U., Cakar, A., Dogan, H., Abaci, N., Ustek, D., Sayood, K., \& Can, H. (2014). Metagenomic analysis of the microbial community in kefir grains. Food Microbiology, 41, 42-51. 
Pan, Y., Rowney, M., Guo, P., \& Hobman, P. (2007). Biological properties of lactoferrin: an overview. Australian Journal of Dairy Technology, 62(1), 31-42.

Pihlanto, A., \& Korhonen, H. (2015). Bioactive peptides from fermented foods and health promotion. In Advances in fermented foods and beverages (pp. 39-74): Elsevier.

Pimentel-Nunes, P., Soares, J. B., Roncon-Albuquerque Jr, R., Dinis-Ribeiro, M., \& Leite-Moreira, A. F. (2010). Toll-like receptors as therapeutic targets in gastrointestinal diseases. Expert Opinion on Therapeutic Targets, 14(4), 347-368.

Pisanu, S., Pagnozzi, D., Pes, M., Pirisi, A., Roggio, T., Uzzau, S., \& Addis, M. F. (2015). Differences in the peptide profile of raw and pasteurised ovine milk cheese and implications for its bioactive potential. International Dairy Journal, 42, 26-33.

Purutoğlu, K., İspirli, H., Yüzer, M. O., Serencam, H., \& Dertli, E. (2020). Diversity and functional characteristics of lactic acid bacteria from traditional kefir grains. International Journal of Dairy Technology, 73(1), 57-66.

Rezac, S., Kok, C. R., Heermann, M., \& Hutkins, R. (2018). Fermented foods as a dietary source of live organisms. Frontiers in Microbiology, 9, 1-29.

Ritchie, M. L., \& Romanuk, T. N. (2012). A meta-analysis of probiotic efficacy for gastrointestinal diseases. PloS One, 7(4), 1-11.

Rosenfeldt, V., Michaelsen, K. F., Jakobsen, M., Larsen, C. N., Møller, P. L., Tvede, M., Weyrehler, H., Valerius, N.H. \& Paerregaard, A. (2002). Effect of probiotic Lactobacillus strains in young children hospitalized with acute diarrhea. The Pediatric Infectious Disease Journal, 21(5), 411-416.

Ryan, K. A., Daly, P., Li, Y., Hooton, C., \& O'Toole, P. W. (2008). Strain-specific inhibition of Helicobacter pylori by Lactobacillus salivarius and other lactobacilli. Journal of Antimicrobial Chemotherapy, 61(4), 831-834.

Saadat, Y. R., Khosroushahi, A. Y., \& Gargari, B. P. (2019). A comprehensive review of anticancer, immunomodulatory and health beneficial effects of the lactic acid bacteria exopolysaccharides. Carbohydrate Polymers, 217, 79-89.

Santagati, M., Scillato, M., Muscaridola, N., Metoldo, V., La Mantia, I., \& Stefani, S. (2015). Colonization, safety, and tolerability study of the Streptococcus salivarius 24SMBc nasal spray for its application in upper respiratory tract infections. European Journal of Clinical Microbiology \& Infectious Diseases, 34(10), 2075-2080.

Sengun, I. Y., Nielsen, D. S., Karapinar, M., \& Jakobsen, M. (2009). Identification of lactic acid bacteria isolated from Tarhana, a traditional Turkish fermented food. International Journal of Food Microbiology, 135(2), 105111.

Serkedjieva, J., Danova, S., \& Ivanova, I. (2000). Antiinfluenza virus activity of a bacteriocin produced by Lactobacillus delbrueckii. Applied Biochemistry and Biotechnology, 88(1-3), 285-298.

Siciliano, R., Rega, B., Marchetti, M., Seganti, L., Antonini, G., \& Valenti, P. (1999). Bovine lactoferrin peptidic fragments involved in inhibition of herpes simplex virus type 1 infection. Biochemical and Biophysical Research Communications, 264(1), 19-23.

Soedamah-Muthu, S. S., Masset, G., Verberne, L., Geleijnse, J. M., \& Brunner, E. J. (2013). Consumption of dairy products and associations with incident diabetes, CHD and mortality in the Whitehall II study. British Journal of Nutrition, 109(4), 718-726.

Solieri, L., De Vero, L., \& Tagliazucchi, D. (2018). Peptidomic study of casein proteolysis in bovine milk by Lactobacillus casei PRA205 and Lactobacillus rhamnosus PRA331. International Dairy Journal, 85, 237-246.

Sousa, M. A. d., Rama, G. R., Volken de Souza, C. F., \& Granada, C. E. (2020). Acid lactic lactobacilli as a biotechnological toll to improve food quality and human health. Biotechnology Progress, 36(2), 1-15.

Stjernquist-Desatnik, A. (2000). Persistence of Lactobacillus plantarum DSM 9843 on human tonsillar surface after oral administration in fermented oatmeal gruel: A pilot study. Acta Oto-Laryngologica, 120(543), 215-219.

Sugimura, T., Takahashi, H., Jounai, K., Ohshio, K., Kanayama, M., Tazumi, K., Tanihata, Y., Miura, Y., Fujiwara, D., \& Yamamoto, N. (2015). Effects of oral intake of plasmacytoid dendritic cells-stimulative lactic acid bacterial strain on pathogenesis of influenza-like illness and immunological response to influenza virus. British Journal of Nutrition, 114(5), 727-733.

Szwajkowska, M., Wolanciuk, A., Barłowska, J., Krol, J., \& Litwińczuk, Z. (2011). Bovine milk proteins as the source of bioactive peptides influencing the consumers' immune system-a review. Animal Science Papers and Reports, 29(4), 269-280.

Tapiovaara, L., Pitkaranta, A., \& Korpela, R. (2016). Probiotics and the upper respiratory tract-a review. Pediatric Infectious Disease, 1(19), 1-8.

Taş, T. K., Ekinci, F. Y., \& Guzel-Seydim, Z. B. (2012). Identification of microbial flora in kefir grains produced in Turkey using PCR. International Journal of Dairy Technology, 65(1), 126-131.

Taverniti, V., \& Guglielmetti, S. (2011). The immunomodulatory properties of probiotic microorganisms beyond their viability (ghost probiotics: proposal of paraprobiotic concept). Genes \& Nutrition, 6(3), 261.

Todorov, S. D., Wachsman, M., Tomé, E., Dousset, X., Destro, M. T., Dicks, L. M. T., de Melo-Franco, B. D. G., Vaz-Velho, M., Drider, D. (2010). Characterisation of an antiviral pediocin-like bacteriocin produced by Enterococcus faecium. Food Microbiology, 27(7), 869-879.

Todorov, S. D., Wachsman, M. B., Knoetze, H., Meincken, M., \& Dicks, L. M. T. (2005). An antibacterial and antiviral peptide produced by Enterococcus mundtii ST4V isolated from soya beans. International Journal of Antimicrobial Agents, 25(6), 508-513.

Tomosada, Y., Chiba, E., Zelaya, H., Takahashi, T., Tsukida, K., Kitazawa, H., Alvarez, S., \& Villena, J. (2013). Nasally administered Lactobacillus rhamnosus strains differentially modulate respiratory antiviral immune responses and induce protection against respiratory syncytial virus infection. BMC Immunology, 14(1), 40.

Tonolo, F., Fiorese, F., Moretto, L., Folda, A., Scalcon, V., Grinzato, A., Ferro, S., Arrigoni, G., Bindoli, Alberto., Feller, E., Bellamio, M., Marin, O., \& Rigobello, M.P. (2020). Identification of new peptides from fermented milk showing antioxidant properties: Mechanism of action. Antioxidants, 9(2), 117.

Torres, N. I., Noll, K. S., Xu, S., Li, J., Huang, Q., Sinko, P. J., Wachsman, M. B., \& Chikindas, M. L. (2013). Safety, formulation and in vitro antiviral activity of the antimicrobial peptide subtilosin against herpes simplex 
virus type 1. Probiotics and Antimicrobial Proteins, 5(1), 26-35.

Tsai, Y.-T., Cheng, P.-C., \& Pan, T.-M. (2012). The immunomodulatory effects of lactic acid bacteria for improving immune functions and benefits. Applied Microbiology and Biotechnology, 96(4), 853-862.

Tuyama, A. C., Cheshenko, N., Carlucci, M. J., Li, J.-H., Goldberg, C. L., Waller, D. P., Anderson, R. A., Profy, A. T., Klotman, M. E., Keller, M. J., \& Herold, B. C. (2006). ACIDFORM inactivates herpes simplex virus and prevents genital herpes in a mouse model: optimal candidate for microbicide combinations. The Journal of Infectious Diseases, 194(6), 795-803.

Wachsman, M. B., Castilla, V., de Ruiz Holgado, A. P., de Torres, R. A., Sesma, F., \& Coto, C. E. (2003). Enterocin CRL35 inhibits late stages of HSV-1 and HSV-2 replication in vitro. Antiviral Research, 58(1), 17-24.

Wagner, R., \& Balish, E. (1998). Potential hazards of probiotic bacteria for immunodeficient patients. Bulletin de I'Institut Pasteur, 96(3), 165-170.

Waki, N., Yajima, N., Suganuma, H., Buddle, B., Luo, D., Heiser, A., \& Zheng, T. (2014). Oral administration of
Lactobacillus brevis KB 290 to mice alleviates clinical symptoms following influenza virus infection. Letters in Applied Microbiology, 58(1), 87-93.

Wang, H., Livingston, K. A., Fox, C. S., Meigs, J. B., \& Jacques, P. F. (2013). Yogurt consumption is associated with better diet quality and metabolic profile in American men and women. Nutrition Research, 33(1), 18-26.

Wang, Z., Chai, W., Burwinkel, M., Twardziok, S., Wrede, P., Palissa, C., Esch, B., \& Schmidt, M. F. (2013). Inhibitory influence of Enterococcus faecium on the propagation of swine influenza A virus in vitro. PloS One, 8(1).

Yang, Y., Song, H., Wang, L., Dong, W., Yang, Z., Yuan, P., Wang, K., \& Song, Z. (2017). Antiviral effects of a probiotic metabolic products against transmissible gastroenteritis coronavirus. Journal of Probiotics and Health, 5(3), 1-6.

Yeo, J.-M., Lee, H.-J., Kim, J.-W., Lee, J.-B., Park, S.-Y., Choi, I.S., \& Song, C.-S. (2014). Lactobacillus fermentum CJL-112 protects mice against influenza virus infection by activating T-helper 1 and eliciting a protective immune response. International Immunopharmacology, 18(1), 50-54. 